\title{
An end to psychiatric detention? Implications of the United Nations Convention on the Rights of Persons with Disabilities
}

\author{
Brendan D. Kelly
}

\section{Summary}

The United Nations Convention on the Rights of Persons with Disabilities is a welcome articulation of the rights of the disabled. However, as its definition of disability appears to include mental illness, the UK appears to violate it by linking mental illness with detention. Clarity and, possibly, change are needed.

\section{Declaration of interest}

None.
Brendan D. Kelly is associate clinical professor of psychiatry at University College Dublin and a consultant psychiatrist at the Mater Misericordiae University Hospital, Dublin. In addition to his medical degree, he holds doctorates in medicine (MD), history (PhD), governance (DGov) and law (PhD).

The Convention on the Rights of Persons with Disabilities is an international human rights document that was adopted by the United Nations in 2006 and came into effect in 2008. ${ }^{1}$ The Convention aims 'to promote, protect and ensure the full and equal enjoyment of all human rights and fundamental freedoms by all persons with disabilities, and to promote respect for their inherent dignity' (Article 1). By June 2013 the Convention had 155 signatories and had been ratified by 132 parties, including the European Union. The UK signed it in 2007 and ratified it in 2009, albeit with specific reservations (unrelated to mental disorder). Ireland signed it in 2007 but has not yet ratified it owing to the absence of up-to-date capacity legislation, which is currently being formulated.

The Convention represents a long overdue and welcome articulation of the rights of people with disabilities. In the context of psychiatry, however, the Convention raises several important issues, most notably in relation to its definition of disability and the United Nations' position on legislation which uses mental disorder as part of criteria for deprivation of liberty.

Regarding definitions, the Convention states that 'persons with disabilities include those who have long-term physical, mental, intellectual or sensory impairments which in interaction with various barriers may hinder their full and effective participation in society on an equal basis with others' (Article 1). ${ }^{1}$ On the face of it, this definition does not appear explicitly to include all people with mental disorder, because many mental disorders are not 'long-term'. Under the UK's Mental Health Act 1983 (amended in 2007), 'mental disorder' means 'any disorder or disability of the mind' (Section 1). The Convention on the Rights of Persons with Disabilities does not, however, present its definition of 'persons with disabilities' as a comprehensive one but states instead that the term 'persons with disabilities' includes people with 'long-term' impairments; others, presumably, may also fit the definition. On this basis, it is likely that some people with mental disorder meet the definition at least some of the time (for example an individual with long-term impairment resulting from chronic schizophrenia or with intellectual disability) but others do not (for example an individual with a single episode of depression).

Regarding 'disability', the Convention states 'that disability is an evolving concept and that disability results from the interaction between persons with impairments and attitudinal and environmental barriers that hinders their full and effective participation in society on an equal basis with others' (preamble). Unlike the Convention's definition of 'persons with disabilities', this conceptualisation of 'disability' holds particular resonance in psychiatry. The stigma associated with mental disorder stems largely from just such 'attitudinal and environmental barriers' that hinder 'full and effective participation in society', often resulting in social exclusion and denial of rights among certain people with mental disorders. ${ }^{2}$

\section{Mental health legislation}

Turning to the issue of detention, the Convention requires that 'states parties shall ensure that persons with disabilities, on an equal basis with others: (a) Enjoy the right to liberty and security of person; (b) Are not deprived of their liberty unlawfully or arbitrarily, and that any deprivation of liberty is in conformity with the law, and that the existence of a disability shall in no case justify a deprivation of liberty' (Article 14). ${ }^{1}$ If mental disorder is included within the Convention definition of disability, then this provision of the Convention suggests that mental health legislation that includes the presence of mental disorder in the criteria for deprivation of liberty violates the Convention. In 2009, the United Nations High Commissioner for Human Rights objected especially strongly to any link between 'preventive detention' and risk to self or others stemming from 'mental illness':

Legislation authorising the institutionalisation of persons with disabilities on the grounds of their disability without their free and informed consent must be abolished. This must include the repeal of provisions authorising institutionalisation of persons with disabilities for their care and treatment without their free and informed consent, as well as provisions authorising the preventive detention of persons with disabilities on grounds such as the likelihood of them posing a danger to themselves or others, in all cases in which such grounds of care, treatment and public security are linked in legislation to an apparent or diagnosed mental illness. This should not be interpreted to say that persons with disabilities cannot be lawfully subject to detention for care and treatment or to preventive detention, but that the legal grounds upon which restriction of liberty is determined must be de-linked from the disability and neutrally defined so as to apply to all persons on an equal basis. (paragraph 49) ${ }^{3}$ 
This passage suggests that the UK's mental health legislation violates United Nations human rights standards by including both 'mental disorder' and risk to self or others in the criteria for detention (Mental Health Act 1983, Sections 2-5). A similar situation pertains in Ireland where a person can be detained under mental health legislation if he or she has a 'mental disorder' that results in 'a serious likelihood of the person concerned causing immediate and serious harm to himself or herself or to other persons' (Mental Health Act 2001, Section 3). Unlike the UK, however, Ireland has not yet ratified the Convention, so the Convention has less effect in Ireland.

Notwithstanding the apparent tension between the Mental Health Act 1983 and the Convention, the UK government, in its first report on implementing the Convention, stated that 'no one in the UK can be deprived of his or her liberty because he or she is disabled' (paragraph 133). ${ }^{4}$ Although it is true that no one in the UK can be detained solely because he or she has a mental disorder (other criteria must be fulfilled), the United Nations High Commissioner for Human Rights is clear that 'disability' must not be linked in any way with deprivation of liberty. ${ }^{3}$

The view of the United Nations High Commissioner is supported by the Committee on the Rights of Persons with Disabilities, a body of independent experts that monitors implementation of the Convention. In its 2011 report on Spain, the Committee recommended that Spain 'review its laws that allow for the deprivation of liberty on the basis of disability, including mental, psychosocial or intellectual disabilities; repeal provisions that authorize involuntary internment linked to an apparent or diagnosed disability; and adopt measures to ensure that health-care services, including all mental-health-care services, are based on the informed consent of the person concerned' (paragraph 36$)^{5}$

\section{Detention, risk and mental disorder}

The UK's Mental Health Act 1983 draws clear links between detention, risk and mental disorder (Sections $2-5$ ). In the process that led to the Mental Health Act amendments in 2007, these links were considered with care by the 'Expert Committee' charged with advising the government on the new legislation. ${ }^{6}$ The Committee noted that a 'small minority' believed that 'a mental health act should authorise treatment in the absence of consent only for those who lack capacity' and 'if a person with a mental disorder who refused treatment was thought to pose a serious risk to others then he or she should be dealt with through the criminal justice system, not through a health provision'. ${ }^{6}$ There was, however, 'a much larger body of opinion which was prepared to accept the overriding of a capable refusal in a health provision on grounds of public safety in certain circumstances'. The Committee inclined towards the latter view:

The reasons given were in part pragmatic and in part driven by principle. Essentially most of those who commented accepted that the safety of the public must be allowed to outweigh individual autonomy where the risk is sufficiently great and, if the risk is related to the presence of a mental disorder for which a health intervention of likely benefit to the individual is available, then it is appropriate that such intervention should be authorised as part of a health provision. Mental disorder unlike most physical health problems may occasionally have wider consequences for the individual's family and carer, and very occasionally for unconnected members of the public affected by the individual's behaviour, acts and omissions. The committee supports this reasoning and in what follows we seek to describe a framework which adequately reflects it. (p. 19)

As a result, the UK's amended Mental Health Act still links detention with risk and mental disorder. The present position in the UK in this, and other regards, is moderately compatible with the human rights standards for mental health legislation outlined by the World Health Organization ${ }^{7}$ and UK case law has also been clearly influenced, at least in part, by rulings of the European Court of Human Rights. ${ }^{8}$ But whether or not the current position represents a violation of the Convention on the Rights of Persons with Disabilities depends on whether or not the Convention's definition of disability includes mental disorder. All the indications from the United Nations are that it does, but this needs clarification.

If mental disorder is included within the United Nations definition of 'disability', this will have the positive effect of affording the protections and supports of the Convention to individuals with mental disorder. There will, however, be other implications, not least of which is the pressure that ratifying countries, including the UK, would come under to revise mental health legislation so as to de-link psychiatric detention from risk stemming from mental disorder.

Such a de-linking would affect mental health legislation in many jurisdictions, a majority of which link involuntary admission with 'mental disorder' or 'mental illness.' The precise effects of de-linking of psychiatric detention from risk stemming from mental disorder would, however, differ across jurisdictions, owing to differing legal arrangements at national level including, most notably, differing levels of protection of the right to freedom. ${ }^{10}$ For most jurisdictions, however, there is little doubt that such a change would represent a radical departure from the present position, and there is little evidence that any jurisdiction, including the UK, is ready for such profound change.

Brendan D. Kelly, MB, BCh, BAO, MA, MSC, MA, MD, PhD, DGov, PhD, FRCPI, FRCPsych, Department of Adult Psychiatry, University College Dublin, Mater Misericordiae University Hospital, 62/63 Eccles Street, Dublin 7, Ireland. Email: brendankelly35@gmail.com

First received 15 Jul 2013, final revision 8 Nov 2013, accepted 28 Nov 2013

\section{References}

1 United Nations. Convention on the Rights of Persons with Disabilities. United Nations, 2006

2 Kelly BD. Structural violence and schizophrenia. Soc Sci Med 2005; 61 721-30.

3 United Nations High Commissioner for Human Rights. Annual Report of the United Nations High Commissioner for Human Rights and Reports of the Office of the High Commissioner and the Secretary General: Thematic Study by the Office of the United Nations High Commissioner for Human Rights on Enhancing Awareness and Understanding of the Convention on the Rights of Persons with Disabilities. United Nations, 2009.

4 Office for Disability Issues. UK Initial Report on the UN Convention on the Rights of Persons with Disabilities. HM Government, 2009.

5 Committee on the Rights of Persons with Disabilities. Concluding Observations of the Committee on the Rights of Persons with Disabilities: Spain. United Nations, 2011.

6 Expert Committee. Review of the Mental Health Act 1983. Department of Health, 1999.

7 Kelly BD. Mental health legislation and human rights in England, Wales and the Republic of Ireland. Int J Law Psychiatry 2011; 34: 439-54.

8 Fennell P. Mental Health: The New Law. Jordan Publishing Limited, 2007.

9 Kallert TW, Rymaszewska J, Torres-González F. The clinical point of view: comparing differences of legal regulations related to involuntary admission and hospital stay in twelve European countries. In Legislation on Coercive Mental Health Care in Europe (eds TW Kallert, F Torres-González): 375-400. Peter Lang, 2006.

10 Conrady J, Roeder T. The legal point of view: comparing differences of legal regulations related to involuntary admission and hospital stay in twelve European countries. In Legislation on Coercive Mental Health Care in Europe (eds TW Kallert, F Torres-González): 349-74. Peter Lang, 2006. 